\title{
Enzymatic and morphometric evidence for Crohn's disease as a diffuse lesion of the gastrointestinal tract
}

\author{
W. T. DUNNE, W. T. COOKE AND R. N. AllAN, \\ From the Department of Biological Science, University of Aston in Birmingham, \\ and the Nutritional and Intestinal Unit, The General Hospital, Birmingham
}

SUMMARY Intestinal disaccharidase and dipeptidase activities were measured in mucosal biopsies from the proximal jejunum in 20 patients with Crohn's disease apparently confined to the distal ileum or large bowel, 14 patients with ulcerative colitis, and 14 healthy volunteers who acted as controls. The dissecting microscopy and histological appearance of the biopsies were normal (Gd 0-1) except for two which showed grade 2 changes. Biopsy morphometry showed a reduction of jejunal mucosal surface area and an increase in mucosal volume in patients with Crohn's disease when compared with the other two groups. The mucosal enzymes studies demonstrated that patients with Crohn's disease had a significant reduction in brush-border enzymes (disaccharidase) but no change in cytoplasmic enzyme activity (dipeptidases). The enzyme levels in patients with ulcerative colitis did not differ from the healthy controls. The reduction of brush-border enzymes with normal cytoplasmic enzymes in the presence of abnormal morphometry is further evidence of the concept of Crohn's disease as a diffuse lesion of the gastrointestinal tract. It also suggests that there is either specific damage to the microvilli or some other abnormality such as impairment of enzyme synthesis.

Crohn's disease may involve any part of the gastrointestinal tract. The extent of the involvement is usually based on radiological, macroscopic, or routine histological examination. These criteria alone probably underestimate the diffuse nature of the disease process. We have previously reported a reduction in bidirectional sodium flux across apparently normal intestinal mucosa (Allan et al., 1974) and an increase in inflammatory cell infiltrate of apparently normal proximal jejunal mucosa in patients with Crohn's disease (Ferguson et al., 1975). This concept has received further support from the work of Goodman et al. (1976), who reported increased glucosamine synthetase activity in biopsies from the rectal mucosa in patients where Crohn's disease was apparently confined to the small bowel or proximal colon.

There have been few studies of the changes in jejunal disaccharidase activity in patients with Crohn's disease. Chalfin and Holt (1967) reported abnormal oral lactose tolerance tests in three out of five patients with Crohn's disease, suggesting lactase deficiency. Littman et al. (1968) reported lactase deficiency in five out of 11 jejunal biopsies from patients with Crohn's disease. As far as we are aware only Sadikali (1971) has studied dipeptidase activity in the jejunal mucosa of Crohn's disease. He measured leucyl glycine dipeptidase, glycylleucine, and glycyl-glycine in the jejunal mucosa from four patients with Crohn's disease. All enzyme levels were lower than those in the control group but only glycyl-glycine dipeptidase was significantly reduced.

In this study the surface area and mucosal volume of the proximal jejunal, brush-border enzymes and cytoplasmic enzymes were studied in patients with distal Crohn's disease using patients with ulcerative colitis and healthy volunteers as controls. The object of the investigation was to determine whether there were changes in jejunal mucosal enzymes in patients with Crohn's disease which would support the concept of Crohn's disease as a diffuse lesion of the gastrointestinal tract and provide a method of identifying the site of abnormality.

\section{Methods}

PATIENTS

Twenty patients with Crohn's disease apparently 
confined to the distal ileum or colon were studied (Table). Thirteen patients had previously undergone surgical resection of either the distal ileum or colon and in each case the macroscopic and histological features were characteristic of Crohn's disease. The diagnosis in the other seven patients was based on radiological findings with involvement of the distal ileum in two cases, distal ileum and colon in two, and assymetrical involvement of the colon with rectal sparing in the other three (one of whom had epitheioid granulomas and giant cells on rectal biopsy). Fourteen patients with ulcerative colitis and 14 normal volunteers acted as controls. All the normal volunteers were in good health.

\section{JEJUNAL BIOPSY}

The jejunal biopsies were obtained from the proximal jejunum, distal to the ligament of Treitz, using the biopsy capsule of Roy-Choudhury and Cooke (1964). The biopsy specimens were divided into two parts, one part was fixed in formol saline for histological examination and the other wrapped tightly in aluminium foil and stored at $-20^{\circ} \mathrm{C}$ prior to enzyme assay.

\section{HISTOLOGY}

All biopsies were examined initially by dissecting and light microscopy. Subsequently two morphometric indices were measured using minor modifications of the method Dunnill and Whitehead (1972). Each biopsy was projected on to a template consist- ing of a series of parallel and vertical lines. The number of times that these lines cut the epithelial surface (E) and the muscularis mucosa $(M)$ were counted and recorded. The number of times the intersection of the lines coincided with the lamina propria (L) were counted and recorded. The ratio $E: M$ gave an index of surface area and $L: M$ an index of mucosal volume. At least six fields were counted for each biopsy.

\section{TISSUE PREPARATION}

The jejunal biopsies were homogenised in double distilled water. The disaccharidase assay was carried out on uncentrifuged homogenate while the dipeptidase were measured in the supernatant fraction obtained by ultra centrifugation.

\section{DISACCHARIDASE ASSAY}

The method of Dahlquist (1968) was used to measure the enzyme activity against the substrates lactose, trehalose, and sucrose. The enzyme activities were expressed in International Units (IU) per gram of protein.

\section{DIPEPTIDASE ASSAY}

The method of Josefsson and Lindberg (1965) was used to measure the enzyme activity against the substrates 1-leucyl-1-leucine, 1-leucyl-glycine, glycyl-1glutamic acid, and glycyl-1-leucine. Enzyme activities were expressed in IU per mg of protein.

Table Clinical and laboratory data of patients with Crohn's disease

\begin{tabular}{|c|c|c|c|c|c|c|c|c|}
\hline \multirow[t]{2}{*}{ Patient } & \multirow{2}{*}{$\begin{array}{l}\text { Age }(y r), \\
\operatorname{sex}\end{array}$} & \multirow{2}{*}{$\begin{array}{l}\text { Duration of disease } \\
\text { (yr) from onset } \\
\text { of symptoms }\end{array}$} & \multirow{2}{*}{ Surgery } & \multirow{2}{*}{$\begin{array}{l}\text { Jejunal } \\
\text { biopsy } \\
\text { histology } \\
(\mathrm{g} / \mathrm{dl})\end{array}$} & \multirow[t]{2}{*}{ Dri'g therapy } & \multicolumn{3}{|c|}{ Current status } \\
\hline & & & & & & $H b g / d l$ & $\begin{array}{l}\text { Albumin } \\
\mathrm{g} / \mathrm{l}\end{array}$ & $\begin{array}{l}\text { Seromucoids } \\
\text { g/l }\end{array}$ \\
\hline MC & $24 \mathrm{~F}$ & 5 & & 2 & $\begin{array}{l}\text { Cortisone acetate } 25 \mathrm{mg} \text { bd } \\
\text { for } 2 \mathrm{yr}\end{array}$ & & & \\
\hline $\mathbf{G M}$ & $16 M$ & 12 & PPC, ileos. & 1 & Nil & $11 \cdot 1$ & 33 & 1.90 \\
\hline FA & $68 \mathrm{M}$ & 16 & & Normal & Nil & $13 \cdot 1$ & 45 & 1.86 \\
\hline VL & $52 \mathrm{~F}$ & 34 & Íleos. col. & Normal & Nil & $15 \cdot 0$ & 43 & 0.66 \\
\hline GW & $38 \mathbf{F}$ & 19 & Il. res. & 1 & Nil & $12 \cdot 2$ & 44 & 1.08 \\
\hline DC & 28M & 5 & \}$_{P P C}$ ileos & Normal & Nil & $10 \cdot 7$ & 24 & $\mathbf{3 \cdot 3 3}$ \\
\hline PH & 43M & 16 & \}PPC, ileos. & Normal & Nil & $13 \cdot 7$ & 40 & 0.29 \\
\hline JH & $47 \mathrm{M}$ & 2 & Illeos., col. & 1 & ACTH $10 \mathrm{u} /$ day for $2 \mathrm{~m}$ & $13 \cdot 0$ & 41 & 1.92 \\
\hline IK & $50 \mathrm{~F}$ & 33 & Il. res. & Normal & $\begin{array}{l}\text { Cortisone acetate } 25 \mathrm{mg} \text { bd } \\
\text { for } 3 \mathrm{yr}\end{array}$ & $13 \cdot 3$ & 31 & $1 \cdot 38$ \\
\hline $\mathrm{JJ}$ & 23M & 18 & Il-caec. res. & 1 & Nil & $13 \cdot 6$ & 36 & $\mathbf{2 \cdot 8 0}$ \\
\hline PG & $34 F$ & 13 & לPPC ileos & 1 & Nil & $12 \cdot 4$ & 35 & $2 \cdot 25$ \\
\hline HL & $47 \mathrm{~F}$ & 18 & YPPC, ileos. & 1 & Nil & $14 \cdot 2$ & 35 & 1.46 \\
\hline TP & $49 \mathrm{M}$ & 1 & & Normal & Nil & $12 \cdot 5$ & 44 & $1 \cdot 11$ \\
\hline GT & $29 \mathrm{~F}$ & 1 & & 1 & Nil & $12 \cdot 1$ & 42 & 0.96 \\
\hline JT & $18 \mathrm{M}$ & 2 & & 1 & Salazopyrin $1 \mathrm{~g}$ bd for $3 \mathrm{w}$ & $9 \cdot 9$ & 31 & $\mathbf{2 \cdot 4 0}$ \\
\hline JN & $28 \mathrm{M}$ & $0 \cdot 3$ & None & 1 & Nil & $8 \cdot 1$ & 25 & 3.93 \\
\hline PH & $24 \mathrm{~F}$ & 1 & & 1 & Nil & $11 \cdot 3$ & 39 & $1 \cdot 20$ \\
\hline $\mathbf{C H}$ & $19 M$ & 6 & & 1 & Salazopyrin $1 \mathrm{~g}$ bd for $2 \mathrm{yr}$ & $15 \cdot 1$ & 42 & 1.54 \\
\hline GT & $29 \mathrm{~F}$ & 1 & & 2 & Nil & $12 \cdot 9$ & 45 & 1.05 \\
\hline SC & 28M & 3 & & 1 & ACTH $20 \mathrm{U} /$ day for $2 \mathrm{w}$ & $11 \cdot 1$ & 30 & $5 \cdot 12$ \\
\hline
\end{tabular}

PPC: Pan proctocolectomy. Ileos.: ileostomy. Col.: colostomy. Il. res.: ileal resection. Il. caec. res.: ileocaecal resection. 


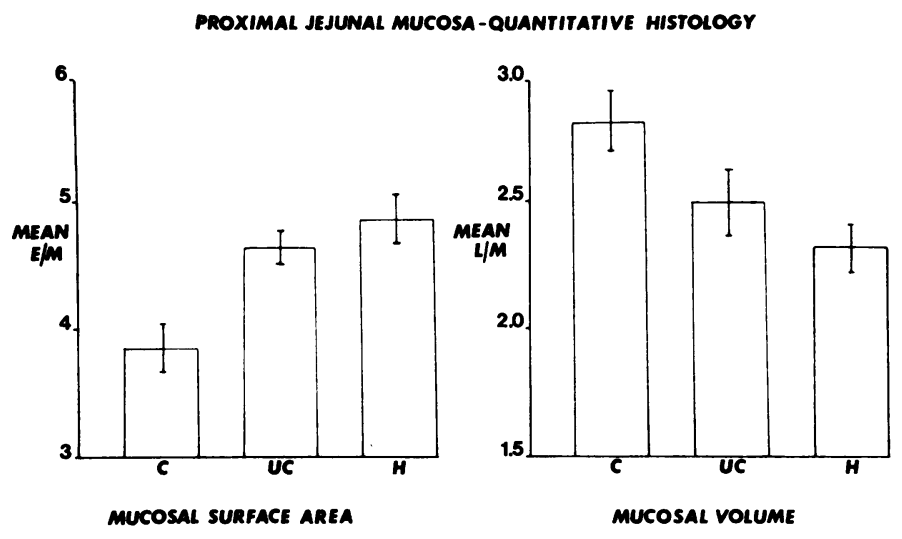

Fig. 1 Morphometry, mucosal volume, and surface area (mean $\pm S E M)$ of the proximal jejunal mucosa in patients with Crohn's disease $(C)$, ulcerative colitis $(U C)$, and healthy controls $(H)$. $E / M$ : index of mucosal surface area, $L / M$ : index of mucosal volume (see text for further details).

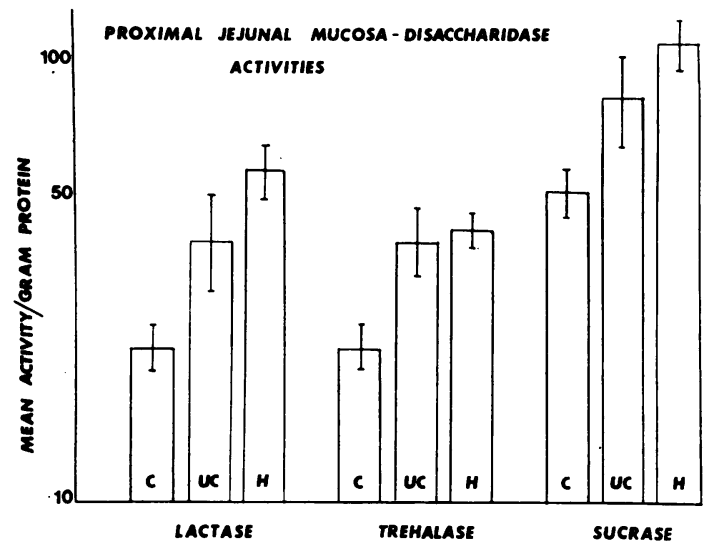

Fig. 2 Disaccharidase activity of the proximal jejunal mucosa in patients with Crohn's disease $(C)$, ulcerative colitis $(U C)$, and healthy controls $(H) .(M e a n \pm S E M)$.

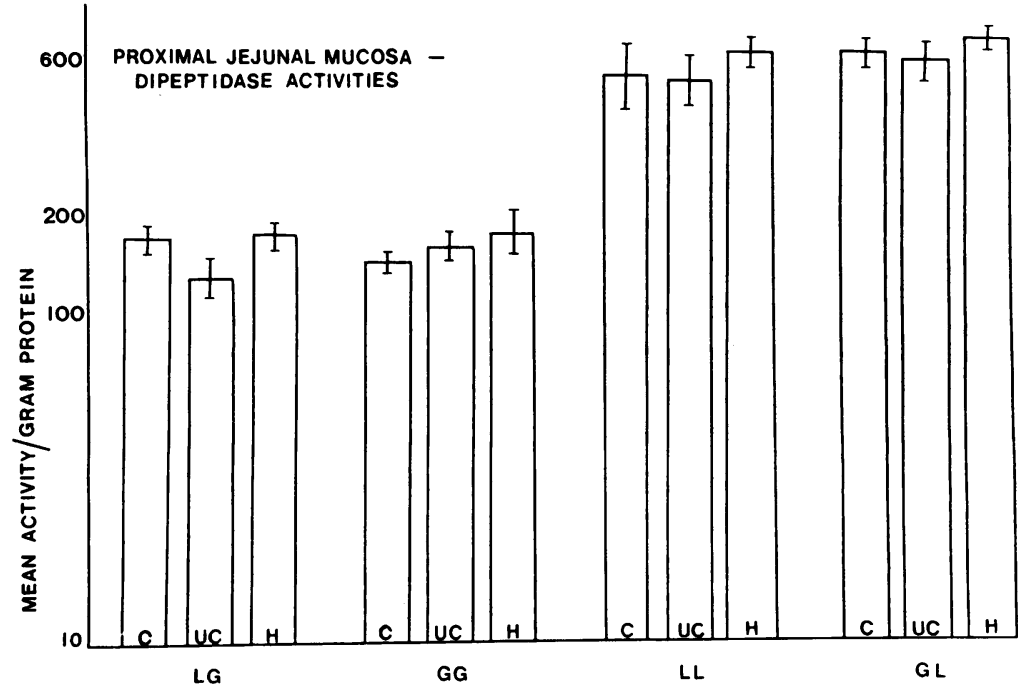

Fig. 3 Dipeptidase activity of the proximal jejunal mucosa in patients with Crohn's disease $(C)$, ulcerative colitis $(U C)$, and healthy controls $(H)$. Mean \pm SEM. LG-1-leucyl-glycine, $G G-$ glycyl-l glutamic acid, LL-1-leucyl-1-leucine, GL-glycyl-1-leucine. 


\section{PROTEIN}

The method of Lowry et al. (1951) was used to measure the protein content of the jejunal biopsies.

\section{OTHER INVESTIGATIONS}

Serum albumin, seromucoids, and haemoglobin were measured in each patient as a quantitative index of disease activity in both Crohn's disease and ulcerative colitis. The disease was considered to be in active phase if the serum albumin was less than $40 \mathrm{~g} / \mathrm{l}$, together with serum seromucoids greater than $1.5 \mathrm{~g} / \mathrm{l}$, and haemoglobin less than $12.5 \mathrm{~g} / \mathrm{dl}$.

\section{DISEASE ACTIVITY}

Five of the patients with Crohn's disease and two patients with ulcerative colitis were considered to have active disease with reduction of serum albumin, haemoglobin, and raised seromucoids (Table).

\section{Results}

\section{HISTOLOGY}

Six patients with Crohn's disease had normal biopsies, 12 grade 1 changes, and two had grade 2 changes. Five of the patients with ulcerative colitis had normal biopsies, eight grade 1 changes, and one had a grade 2 change. Of the normal volunteers seven had normal biopsies and seven had grade 1 changes only.

\section{MORPHOMETRY}

In patients with Crohn's disease the surface area was significantly reduced and the mucosal volume significantly increased compared with patients with ulcerative colitis and healthy controls (Fig. 1). There were no significant differences between patients with ulcerative colitis and the healthy controls (Fig. 1).

\section{ENZYME ASSAYS}

All three disaccharidases were significantly reduced in the patients with Crohn's disease compared with the other two groups (Fig. 2). There were no significant differences in dipeptidase activities between the three groups (Fig. 3).

One patient with Crohn's disease, two with ulcerative colitis, and two of the normal controls were found to have an isolated lactase deficiency.

In the patients with Crohn's disease the changes in morphometry and disaccharidase activity were unrelated to age, sex, length of history, the number of previous resections, steroid therapy, or disease activity.

\section{Discussion}

The morphometric changes in the apparently normal proximal jejunal mucosa in patients with Crohn's disease are consistent with the villous abnormalities described by Shiner and Drury (1962), though such changes have not been identified by other workers (Pena, 1971). The reasons for these differences are not clear but in Pena's study only selected biopsies were examined morphometrically, while the remainder were examined by routine histological methods alone. Studies on the subcellular localisation of dipeptidase activity in guinea-pig small intestine have demonstrated that approximately $90 \%$ of the total activity is located in the cytoplasmic fraction of intestinal homogenate with about $10 \%$ being found in the brush-border fraction (Peters, 1970). The tissue preparation used in this study ensured that only the cytoplasmic dipeptidases were assayed.

We found that the cytoplasmic dipeptidase activity in the jejunal mucosa from patients with Crohn's disease did not differ from healthy controls. This contrasts with the reduction of dipeptidase activity reported by Sadikali (1971), but he used crude homogenates and was thus measuring both cytoplasmic and brush-border enzyme activity.

The reduction of brush-border disaccharidase activity that we observed could be explained in part by the morphological changes of increased mucosal volume and decreased surface area. However, the degree of change and the normal dipeptidase levels suggest that there is a specific abnormality of either the brush border or a reduction of enzyme synthesis in the patients with Crohn's disease.

These morphometric and enzymes changes observed in the proximal jejunal mucosa from patients with Crohn's disease and the absence of such changes in patients with ulcerative colitis and healthy controls is further evidence of a specific abnormality. This is supported by a lack of correlation of morphometric and enzyme changes in the patients with Crohn's disease with age, sex, duration of disease, disease activity, previous resection, or steroid treatment in these patients. These changes in the apparently normal proximal jejunal mucosa add weight to the concept of Crohn's disease as a diffuse lesion of the gastrointestinal tract.

\section{References}

Allan, R. N., Steinberg, D. M., Dixon, K., and Cooke, W. T. (1975). Changes in the bidirectional sodium flux across the intestinal mucosa in Crohn's disease. Gut, 16, 201-204.

Chalfin, D., and Holt, P. R. (1967). Lactase deficiency in ulcerative colitis, regional enteritis and viral hepatitis. American Journal of Digestive Diseases, 12, 81-87.

Dahlquist, A. (1968). Assay of intestinal disaccharidases. Analytical Biochemistry, 22, 99-107.

Dunnill, M. S., and Whitehead, R. (1972). A method for the quantitation of small intestinal biopsy specimens. Journal of Clinical Pathology, 25, 243-246.

Ferguson, R., Allan, R. N., and Cooke, W. T. (1975). A 
study of the cellular infiltrate of the proximal jejunal mucosa in ulcerative colitis and Crohn's disease. Gut, 16, 205-208. Goodman, M. J., Skinner, J. M., and Truelove, S. C. (1976). Abnormalities in the apparently normal bowel mucosa in Crohn's disease. Lancet, 1, 275-278.

Josefsson, L., and Lindberg, T. (1965). Intestinal dipeptidases. 1. Spectrophotometric determination and characterization of dipeptidase activity in pig intestinal mucosa. Biochemica et Biophysica Acta, 105, (1), 149-161.

Littman, A., Cady, A. B., and Rhodes, J. (1968). Lactase and other disaccharidase deficiencies in a hospital population. Israel Journal of Medical Sciences, 4, 110-116.

Lowry, O. H., Rosebrough, N. J., Farr, A. L., and Randall, R. J. (1951). Protein measurement with the Folin phenol reagent. Journal of Biological Chemistry, 193, 265-275.
Pena Ramirez, A. S. (1971). Disaccharidase Activity of the Human Small Intestinal Mucosa. Thesis: Oxford.

Peters, T. J. (1970). The subcellular localization of di- and tri-peptide hydrolase activity in guinea pig small intestine. Biochemical Journal, 120, 195-203.

Roy-Choudhury, D. C., Nicholson, G. I., and Cooke, W. T. (1964). Simple capsule for multiple intestinal biopsy specimens. Lancet, 2, 185-186.

Sadikali, F. (1971). Dipeptidase deficiency and malabsorption of glycyl-glycine in disease states. Gut, 12, 276-283.

Shiner, M., and Drury, R. A. (1962). Abnormalities of the small intestinal mucosa in Crohn's disease (regional enteritis). American Journal of Digestive Diseases, 7, 744-759. 